\title{
Depression and post-traumatic stress disorder in females exposed to intimate partner violence
}

\author{
Youmna Sabri
}

\begin{abstract}
Background: United Nations considered intimate partner violence (IPV) as a serious problem affecting 35\% of females all over the world requesting action to face this problem. There is strong evidence that the effect of violence against women has short-term and long-term negative outcomes on women physical health such as pain, wounds, fractures or even death in addition to serious psychiatric disorders for example anxiety, depression, and post-traumatic stress disorder (PTSD).

The study aims to evaluate the prevalence of different subtypes of (IPV) in a group sample of married females. Also, the current study will examine the relation of intimate partner violence with subsequent depression and posttraumatic stress disorder disorders among those females.

Results: This study highlights subtypes of intimate partner violence among the studied females according to the Composite Abuse Scale (CAS); the highest prevalence type of violence is harassment (72.2\%) followed by physical violence (57.8\%), severe combined violence (54.4\%), emotional violence (53.3\%), and finally the last one is sexual abuse (7.8\%). Post-traumatic stress disorder distribution among studied females; the highest prevalence $(n=37,41.1 \%)$ had mild PTSD, followed by 23 (25.6\%) who were normal, and then $n=20$ (22.2\%) who had severe PTSD, while the least prevalence $(n=10,11.1 \%)$ had moderate PTSD.

In concern to depressive disorder distribution among studied females, the highest prevalence $(n=33,36.7 \%)$ were normal, followed by 29 (32.2\%) who had moderate depression, and then $n=12$ (1.3\%) who had severe depression, $n$ $=9(10.0 \%)$ who had mild depression, while the least prevalence $(n=7,7.8 \%)$ had very severe depressive symptoms.

Conclusions: This study found that the prevalence of intimate partner violence among the studied females is high. In addition, the presence of a strong relationship between all subtypes of intimate partner violence and the diagnosis of PTSD and depressive disorder among studied females. Potential implications; these results can be applied clinically as females are exposed to the burden of IPV and should be helped empowered in various ways such as providing psychiatric counselling for those females.
\end{abstract}

Keywords: Intimate partner violence, Depression, Post-traumatic stress disorder

*Correspondence: youmnasabri@yahoo.com

Department of Psychiatry, Faculty of Medicine, Mansoura University, Mansoura, Egypt

\section{Background}

United Nations considered intimate partner violence (IPV) as a serious problem affecting $35 \%$ of females all over the world requesting an action to face this problem [1].

The World Health Organization in its 2010 report defines IPV as behavior within an intimate relation resulting in physical, sexual, or psychological harm 
such as acts of physical aggression, sexual coercion, psychological abuse, and controlling behaviors [2].

Females are more exposed to fatal injuries by violence, whatever their nationality, education, or socioeconomic level [3].

IPV is uncommon to occur only one time. It is usually characterized by its recurrent occurrence. Despite that, $39 \%$ of IPV is kept secret not documented in a legal form [4].

A recent study [5] reported that in the USA, 22.3\% of women were exposed to physical (IPV), 15.8\% to sexual violence, and $84 \%$ to psychological harm.

In multi-countries study [6], it was found that the prevalence of violence against females is between 15 and $71 \%$ with the least occurrence reported in Japan and the highest prevalencel was reported in Bangladesh and Ethiopia.

The impact of violence against women has short- and long-term negative outcomes on women physical health such as pain, wounds, fractures, or even death in addition to serious psychiatric disorders, for example anxiety, depression, and post-traumatic stress disorder (PTSD) [7].

As the act and the outcome of intimate partner violence are more common to be hidden; this leads to a significant underestimation of the actual frequency and impact of this act [8].

Getting more accurate information about the prevalence and the impact of IPV in society will provide a real chance to improve women mental health and wellbeing.

This study aims to evaluate the prevalence of different subtypes of intimate partner violence in a group sample of married females.

Also, the current study will examine the relation of intimate partner violence with subsequent depression and post-traumatic stress disorder disorders among those females.

\section{Methods}

This study is a cross-sectional study which was done at the Psychiatry Department, Faculty of Medicine, Mansoura University Hospitals (MUH).

The study took place during the period from November 2020 to April 2021 (6-month period), convenience sample of 100 female employees working at the Mansoura University Hospitals (MUH) were asked to join this study due to limited time and cost of the study. The aim of the study was explained to them and they were given the choice to participate or not, they were told that all of their answers would be confidential and written consent will be taken from them. $n=3$ refused to join the study (not interested, personal issues), and $n=7$ were excluded according to exclusion criteria.

Finally, the sample size was ninety $(n=90)$ participants who joined this study.

\section{Inclusion criteria \\ - Female \\ - Married \\ - Age 25-45 \\ - No past or family history of depression before mar- riage.}

\section{Exclusion criteria}

- Age $<25$ years or $>45$ years

- Presence of past or family history of depression before marriage.

Major depressive episodes and post-traumatic stress disorder were assessed clinically in the examined sample with Structured Clinical Interview for DSM-IV (SCID).

\section{Data collection instrument}

The Composite Abuse Scale (CAS)

This scale is a self-report scale to assess violence in intimate relationships.

The Composite Abuse Scale [9, 10], consists of 30 items, measures five types of abuse: (1) severe combined abuse, (2) sexual abuse, (3) emotional abuse, (4) physical abuse, and (5) harassment.

Each item was rated on a 6-point response scale: never (0), only once (1), several times (2), once a month (3), once a week (4), and daily (5). The cutoff score is severe combined abuse $(\geq 1)$, physical abuse $(\geq 1)$, emotional abuse $(\geq 3)$, and harassment $(\geq 2)$.

Harassment is a form of vexatious behavior that involves repeated hostile and unwanted words, behavior, or actions that are painful, hurtful, annoying, humiliating, or insulting. While verbal abuse is a type of psychologi$\mathrm{cal} / \mathrm{mental}$ abuse that involves the use of oral language, gestured language, and written language directed to a victim [11].

Arabic version was prepared by translation and back translation in the Department of Psychiatry, Faculty of Medicine, Mansoura University.

\section{The Hamilton Depression Rating Scale (HDRS)}

It is a questionnaire [12] designed for adults, and Arabic version [13] is used to rate the severity of depression by assessing their mood, feelings of guilt, suicide 
ideation, insomnia, agitation or retardation, anxiety, weight loss, and somatic symptoms. The time is about $20 \mathrm{~min}$. A score of $0-7=$ normal, $8-13=$ mild depression, $14-18=$ moderate depression, $19-22=$ severe depression, $\geq 23$ = very severe depression.

\section{Post-Traumatic Stress Diagnostic Scale (PDS)}

The Post-Traumatic Stress Diagnostic Scale (PDS)Arabic version [14, 15] provides a brief but reliable self-report measure of post-traumatic stress disorder (PTSD) for use in both clinical and research settings. The scale is used to detect the presence of PTSD in persons who were exposed to a traumatic event and to assess symptom severity and functioning. The test is self-administered; the time is within 10-15 min and requires a reading age of 13 years. Questions related to the frequency of re-experience distressing and intrusive thoughts, post-traumatic avoidance, and hyper arousal. The PDS has 49 items. The cut-offs for symptom severity rating are 0 no rating, $1-10$ mild, $11-20$ moderate, 21-35 moderate to severe, and $\geq 36$ severe Table 1 .

Table 1 Socio-demographic data of the studied females

\begin{tabular}{|c|c|c|}
\hline & $n=90$ & $\%$ \\
\hline \multicolumn{3}{|l|}{ Age/years } \\
\hline mean $\pm S D$ & $34.02 \pm 4.85$ & \\
\hline (min-max) & $(26-45)$ & \\
\hline \multicolumn{3}{|l|}{ Residence } \\
\hline Urban & 69 & 76.7 \\
\hline Rural & 21 & 23.3 \\
\hline \multicolumn{3}{|c|}{ Level of education } \\
\hline Intermediate & 15 & 16.6 \\
\hline High & 75 & 83.3 \\
\hline \multicolumn{3}{|l|}{ Years of marriage } \\
\hline$<10$ years & 42 & 46.6 \\
\hline$>10$ years & 48 & 53.3 \\
\hline \multicolumn{3}{|l|}{ No. of children } \\
\hline$<2$ children & 18 & 20 \\
\hline 2-4 children & 59 & 65.5 \\
\hline$>4$ children & 13 & 14.4 \\
\hline \multicolumn{3}{|c|}{ Husband education } \\
\hline Intermediate & 19 & 21.1 \\
\hline High & 71 & 78.8 \\
\hline \multicolumn{3}{|c|}{ Husband employment } \\
\hline Doctor & 5 & 5.5 \\
\hline Engineer & 11 & 12.2 \\
\hline Employee & 47 & 52.2 \\
\hline Teacher & 18 & 20 \\
\hline Others & 9 & 10 \\
\hline
\end{tabular}

\section{Results}

Socio demographic data of the studied females: $n=$ 90 females mean \pm SD is $34.02 \pm 4.85, n=69,76.7 \%$ are urban, $n=21,23.3 \%$ are rural. Level of education: $16.6 \%$ intermediate, $83.3 \%$ high. Years of marriage; $46.6 \%$, < 10 years; $53.3 \%$, > 10 years

No. of children: $20 \%,<2$ children; $65.5 \%, 2-4$ children; $14.4 \%$, > 4 children. Husband education: $21.1 \%$ intermediate, $78.8 \%$ high

Husband employment: $5.5 \%$ doctor, $12.2 \%$ engineer, $52.2 \%$ employee, $20 \%$ teacher, and $10 \%$ others

Table 2 highlights types of intimate partner violence among the studied females according to the Composite Abuse Scale (CAS); the highest prevalence of the type of violence is harassment $(72.2 \%)$ followed by physical violence $(57.8 \%)$, and then severe combined violence (54.4\%) then emotional violence (53.3\%), and finally the last one is sexual abuse (7.8\%).

Table 3 studied post-traumatic stress disorder distribution among studied females; the highest prevalence ( $n=37,41.1 \%$ ) had mild PTSD, followed by 23 (25.6\%) who were normal, and then $n=20(22.2 \%)$ who had severe PTSD, while the least prevalence $(n=10,11.1 \%)$ had moderate PTSD.

Table 2 Types of intimate partner violence among studied females according to the Composite Abuse Scale (CAS)

\begin{tabular}{lll}
\hline & $\boldsymbol{n}=\mathbf{9 0}$ & \% \\
\hline Severe combined violence & 49 & 54.4 \\
Sexual violence & 7 & 7.8 \\
Emotional violence & 48 & 53.3 \\
Physical violence & 52 & 57.8 \\
Harassment & 65 & 72.2 \\
\hline
\end{tabular}

Table 3 Depressive disorder and post-traumatic stress disorder distribution among studied females

\begin{tabular}{lll}
\hline & $\boldsymbol{n}=\mathbf{9 0}$ & \% \\
\hline PTSD & & \\
Normal & 23 & 25.6 \\
Mild & 37 & 41.1 \\
Moderate & 10 & 11.1 \\
Severe & 20 & 22.2 \\
Depressive disorder & & \\
Normal & 33 & 36.7 \\
Mild & 9 & 10.0 \\
Moderate & 29 & 32.2 \\
Severe & 12 & 13.3 \\
Very severe & 7 & 7.8 \\
\hline
\end{tabular}


In concern to depressive disorder distribution among studied females, the highest prevalence $(n=33,36.7 \%)$ were normal, followed by 29 (32.2\%) who had moderate depression, and then $n=12(1.3 \%)$ who had severe depression, $n=9(10.0 \%)$ had mild depression, while the least prevalence $(n=7,7.8 \%)$ had very severe depressive symptoms.

Table 4 revealed the presence of a significant positive relationship $(P<0.001)$ between sexual, emotional, physical violence, and diagnosis of PTSD among studied females.

Table 5 examined a univariate analysis of post-traumatic disorders and types of violence among studied females reporting the presence of a significant positive relationship $(P<0.001)$ between severe combined, emotional, physical violence, and diagnosis of PTSD among studied females.
Figure 1 illustrates a statistically significant positive correlation between sexual violence and post-traumatic stress disorder $(r=0.393)$.

Figure 2 illustrates a statistically significant positive correlation between emotional violence and post-traumatic stress disorder $(r=0.554)$.

Figure 3 illustrates a statistically significant positive correlation between physical violence and post-traumatic stress disorder $(r=0.649)$.

Figure 4 illustrates a statistically significant positive correlation between harassment and post-traumatic stress disorder $(r=0.589)$.

Table 6 examined the relationship between depressive disorder and types of violence among studied females showing that the presence of a significant positive relationship $(P<0.001)$ between all types of intimate partner violence and diagnosis and severity of depressive disorder among studied females.

Table 4 Relation between post-traumatic stress disorders and types of violence among studied females

\begin{tabular}{|c|c|c|c|c|c|c|}
\hline \multicolumn{6}{|l|}{ PTSD } & \multirow[t]{2}{*}{ Test of sig. } \\
\hline & & Normal & Mild & Moderate & Severe & \\
\hline \multirow[t]{2}{*}{ Severe combined } & Negative & $15(36.6)$ & $13(31.7)$ & $5(12.2)$ & $8(19.5)$ & \multirow{2}{*}{$\begin{array}{l}X^{2}=5.53 \\
P=0.137\end{array}$} \\
\hline & Positive & $8(16.3)$ & $24(49.0)$ & $5(10.2)$ & $12(24.5)$ & \\
\hline \multirow[t]{2}{*}{ Sexual violence } & Negative & $23(27.7)$ & $36(43.4)$ & $10(12.0)$ & 14(16.9) & \multirow{2}{*}{$\begin{array}{l}M C \\
P<0.001^{*}\end{array}$} \\
\hline & Positive & 0 & $1(14.3)$ & 0 & $6(85.7)$ & \\
\hline \multirow[t]{2}{*}{ Emotional violence } & Negative & $21(50)$ & $11(26.2)$ & $4(9.5)$ & $6(14.3)$ & \multirow{2}{*}{$\begin{array}{l}M C \\
P<0.001^{*}\end{array}$} \\
\hline & Positive & $2(4.2)$ & $26(54.2)$ & $6(12.5)$ & $14(29.2)$ & \\
\hline \multirow{2}{*}{$\begin{array}{l}\text { Physical } \\
\text { Violence }\end{array}$} & Negative & $19(50)$ & 15(39.5) & 0 & $4(10.5)$ & \multirow{2}{*}{$\begin{array}{l}M C \\
P<0.001^{*}\end{array}$} \\
\hline & Positive & $4(7.7)$ & $22(42.3)$ & 10(19.2) & 16(30.8) & \\
\hline \multirow[t]{2}{*}{ Harassment } & Negative & $10(40)$ & $11(44)$ & $0(0.0)$ & $4(16)$ & \multirow{2}{*}{$\begin{array}{l}M C \\
P=0.062\end{array}$} \\
\hline & Positive & $13(20)$ & $26(40)$ & $10(15.4)$ & $16(24.6)$ & \\
\hline
\end{tabular}

$X^{2}=$ chi-square test, $M C$ Monte Carlo test

*Statistically significant if $P<0.05$

Table 5 Univariate analysis of post-traumatic disorders and types of violence among studied females

\begin{tabular}{|c|c|c|c|c|c|}
\hline & & \multicolumn{2}{|l|}{ PTSD } & \multirow[t]{2}{*}{ Test of sig. } & \multirow{2}{*}{$\begin{array}{l}\text { Odds ratio } \\
(95 \% \mathrm{Cl})\end{array}$} \\
\hline & & Absent & Present & & \\
\hline \multirow[t]{2}{*}{ Severe combined } & Negative & 15(36.6) & $26(63.4)$ & \multirow{2}{*}{$\begin{array}{l}x^{2}=4.82 \\
P=0.028^{*}\end{array}$} & \multirow{2}{*}{$\begin{array}{l}2.96 \\
(1.1-7.95)\end{array}$} \\
\hline & Positive & $8(16.3)$ & $41(83.7)$ & & \\
\hline \multirow[t]{2}{*}{ Sexual violence } & Negative & $23(27.7)$ & $60(72.3)$ & \multirow{2}{*}{$\begin{array}{l}X^{2}=2.61 \\
P=0.106\end{array}$} & \multirow[t]{2}{*}{ Undefined } \\
\hline & Positive & 0 & $7(100)$ & & \\
\hline \multirow[t]{2}{*}{ Emotional violence } & Negative & $21(50)$ & $21(50)$ & \multirow{2}{*}{$\begin{array}{l}X^{2}=24.73 \\
P<0.001^{*}\end{array}$} & \multirow[t]{2}{*}{ 23.93(4.93-107.23) } \\
\hline & Positive & $2(4.2)$ & $46(95.8)$ & & \\
\hline \multirow{2}{*}{$\begin{array}{l}\text { Physical } \\
\text { Violence }\end{array}$} & Negative & $19(50)$ & $19(50)$ & \multirow{2}{*}{$\begin{array}{l}x^{2}=20.66 \\
P<0.001^{*}\end{array}$} & \multirow[t]{2}{*}{$12.0(3.61-39.92)$} \\
\hline & Positive & $4(7.7)$ & 48(92.3) & & \\
\hline \multirow[t]{2}{*}{ Harassment } & Negative & $10(40)$ & $15(60)$ & \multirow{2}{*}{$\begin{array}{l}X^{2}=3.79 \\
P=0.051\end{array}$} & \multirow[t]{2}{*}{$2.67(0.976-7.28)$} \\
\hline & Positive & $13(20)$ & $52(80)$ & & \\
\hline
\end{tabular}

$x^{2}=$ chi-square test

*Statistically significant if $P<0.05$ 


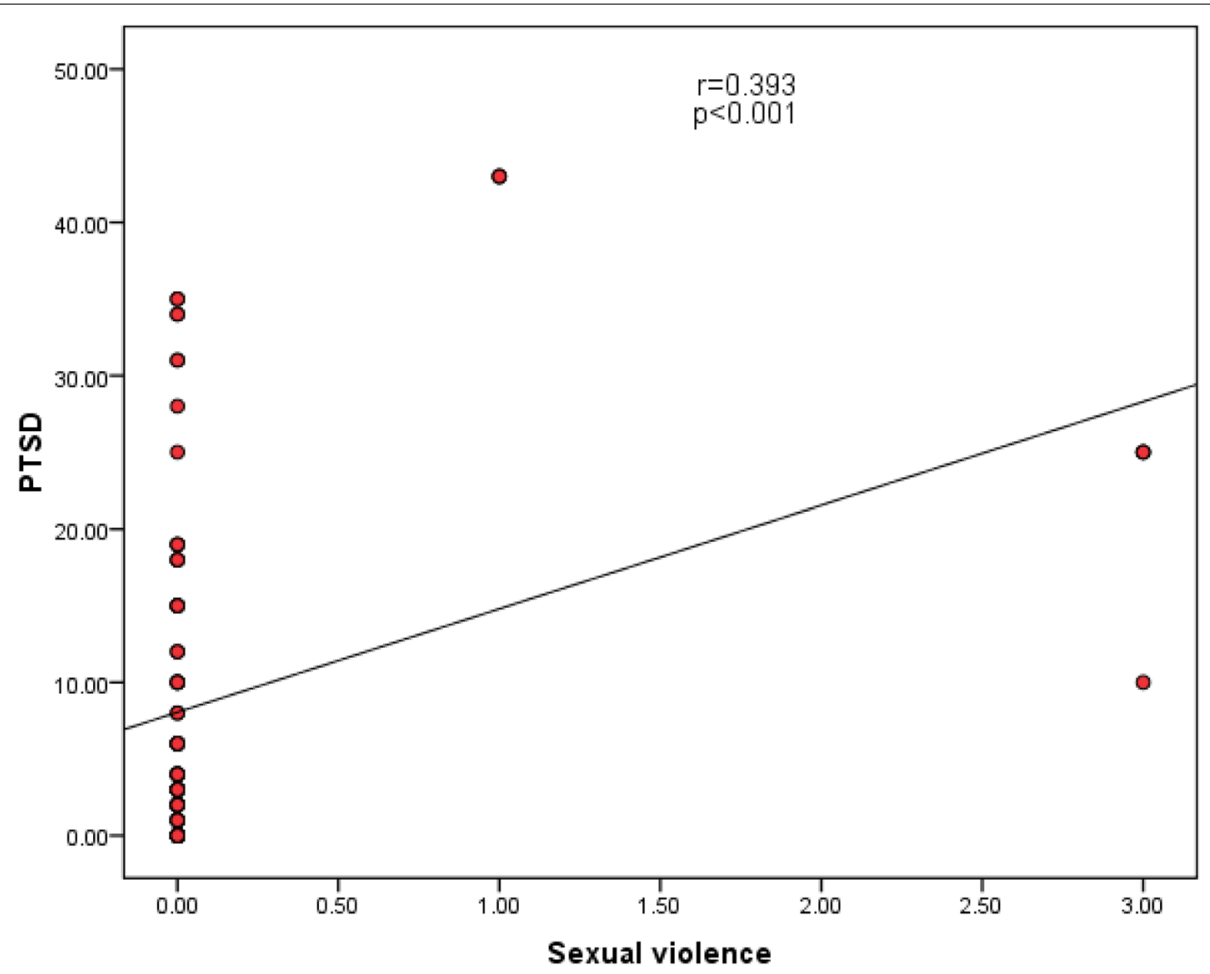

Fig. 1 Scatter diagram showing a correlation between sexual violence and post-traumatic stress disorder

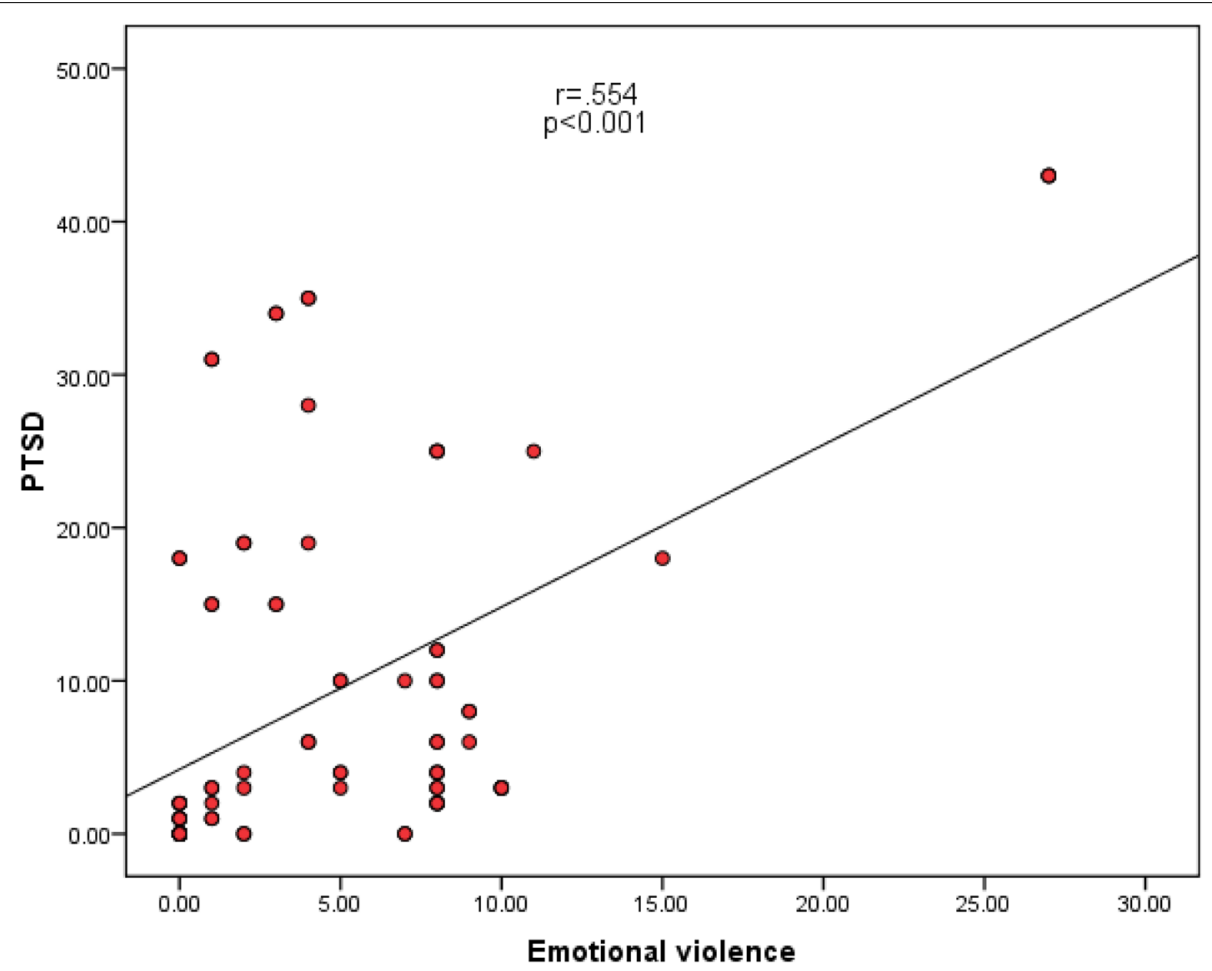

Fig. 2 Scatter diagram showing a correlation between emotional violence and post-traumatic stress disorder 


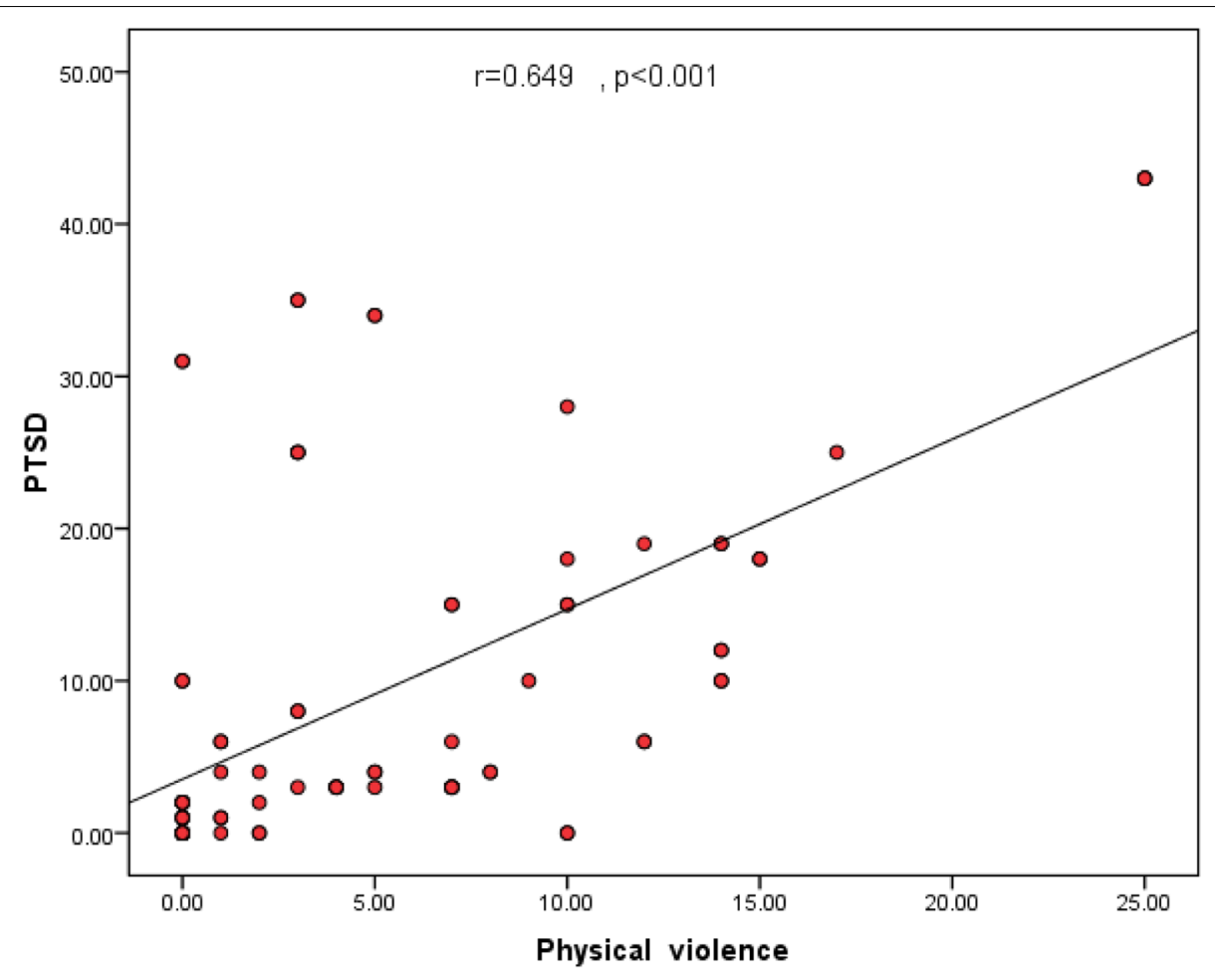

Fig. 3 Scatter diagram showing a correlation between physical violence and post-traumatic stress disorder

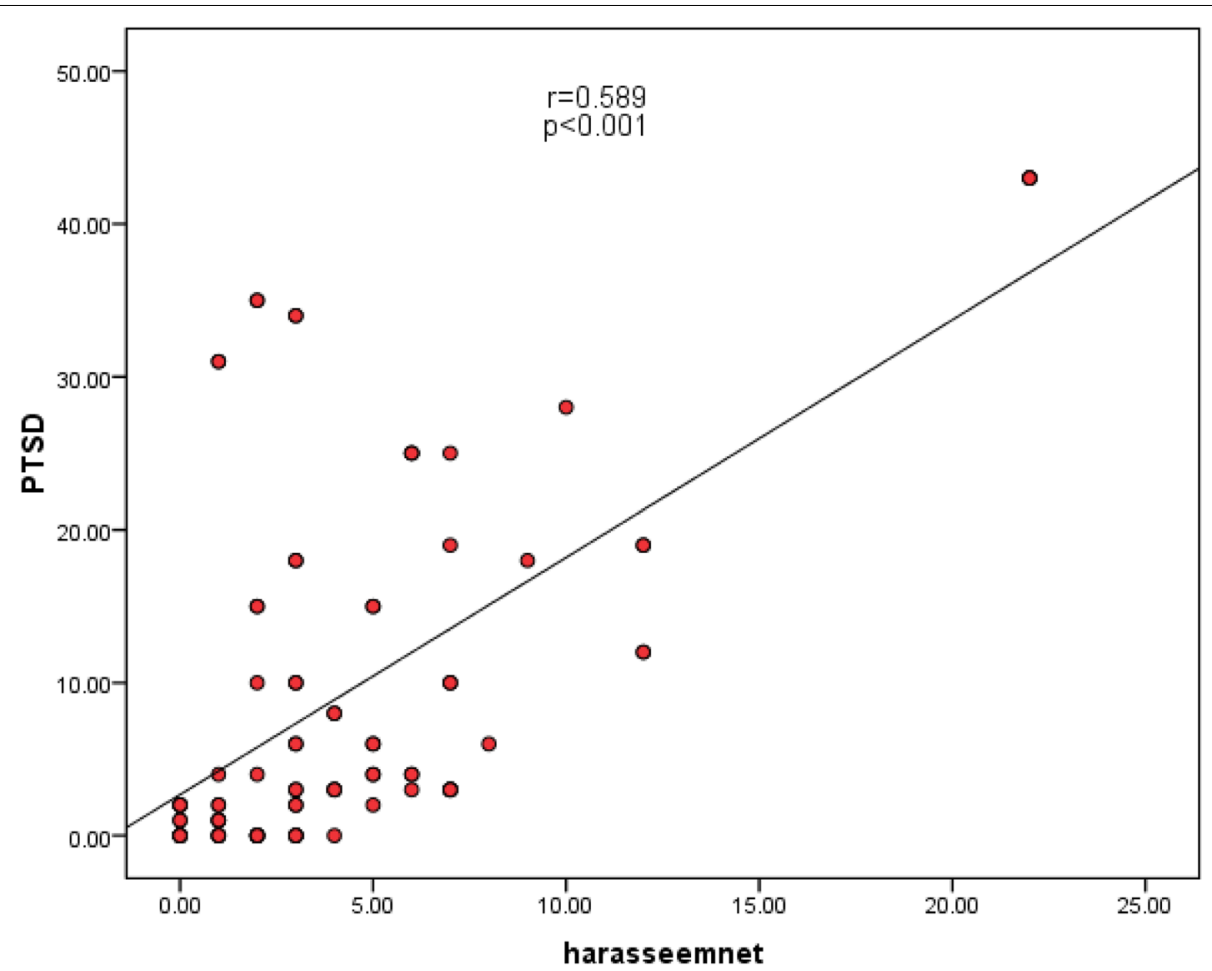

Fig. 4 Scatter diagram showing a correlation between harassment and post-traumatic stress disorder 
Table 6 Relation between depressive disorder and types of violence among studied females

\begin{tabular}{|c|c|c|c|c|c|c|c|}
\hline & & \multicolumn{4}{|c|}{ Depressive disorders } & \multirow[b]{2}{*}{ Very severe } & \multirow[t]{2}{*}{ Test of sig } \\
\hline & & Normal & Mild & Moderate & Severe & & \\
\hline \multirow[t]{2}{*}{ Severe combined } & Negative & $24(58.5)$ & $2(4.9)$ & $9(22.0)$ & 0 & $6(14.6)$ & \multirow{2}{*}{$\begin{array}{l}M C \\
P=0.001^{*}\end{array}$} \\
\hline & Positive & $9(18.4)$ & $7(14.3)$ & $20(40.8)$ & $12(24.5)$ & $1(2.0)$ & \\
\hline \multirow[t]{2}{*}{ Sexual violence } & Negative & 33(39.8) & $8(9.6)$ & 29(34.9) & $6(7.2)$ & $7(8.4)$ & \multirow{2}{*}{$\begin{array}{l}M C \\
P<0.001^{*}\end{array}$} \\
\hline & Positive & 0 & $1(14.3)$ & $0(0.0)$ & $6(85.7)$ & 0 & \\
\hline \multirow[t]{2}{*}{ Emotional violence } & Negative & $28(66.7)$ & $2(4.8)$ & $10(23.8)$ & $0(0.0)$ & $2(4.8)$ & \multirow{2}{*}{$\begin{array}{l}M C \\
P<0.001^{*}\end{array}$} \\
\hline & Positive & $5(10.4)$ & $7(14.6)$ & 19(39.6) & $12(25.0)$ & $5(10.4)$ & \\
\hline \multirow{2}{*}{$\begin{array}{l}\text { Physical } \\
\text { Violence }\end{array}$} & Negative & $30(78.9)$ & $2(5.3)$ & $4(10.5)$ & 0 & $2(5.3)$ & \multirow{2}{*}{$\begin{array}{l}M C \\
P<0.001^{*}\end{array}$} \\
\hline & Positive & $3(5.8)$ & $7(13.5)$ & $25(48.1)$ & $12(23.1)$ & $5(9.6)$ & \\
\hline \multirow[t]{2}{*}{ Harassment } & Negative & 23(92.0) & 0 & 0 & 0 & $2(8)$ & \multirow{2}{*}{$\begin{array}{l}M C \\
P<0.001^{*}\end{array}$} \\
\hline & Positive & $10(15.4)$ & $9(13.8)$ & $29(44.6)$ & $12(18.5)$ & $5(7.7)$ & \\
\hline
\end{tabular}

MC Monte Carlo test

*Statistically significant if $P<0.05$

Table 7 assessed univariate analysis of depressive disorders and types of violence among studied females revealing the presence of a significant positive relationship $(P$ $<0.001$ ) between severe combined, emotional, physical violence, harassment, and diagnosis of depressive disorder among studied females.

Figure 5 illustrates a statistically significant positive correlation between harassment and depressive disorder $(r=0.637)$.

Figure 6 illustrates a statistically significant positive correlation between physical violence and depressive disorder $(r=0.650)$.

Figure 7 illustrates a statistically significant positive correlation between emotional violence and depressive disorder $(r=0.607)$.

Figure 8 illustrates a statistically significant positive correlation between sexual violence and depressive disor$\operatorname{der}(r=0.310)$.
Table 8 studied the correlation between PTSD, depressive disorder and types of intimate partner violence among studied females showing that the presence of a significant positive relationship $(P<0.001)$ between all types of intimate partner violence and diagnosis of PTSD and depressive disorder among studied females.

\section{Statistical analysis and data interpretation}

Data were fed to the computer and analyzed using IBM SPSS Corp. Released 2013. IBM SPSS Statistics for Windows, Version 22.0. Armonk, NY: IBM Corp. Qualitative data were described using numbers and percentages. Quantitative data were described using mean, the standard deviation for parametric data after testing normality using Kolmogorov-Smirnov test. The significance of the obtained results was judged at the $(0.05)$ level.

Table 7 Univariate analysis of depressive disorders and types of violence among studied females

\begin{tabular}{|c|c|c|c|c|c|}
\hline & & \multicolumn{2}{|c|}{ Depressive disorders } & \multirow[t]{2}{*}{ Test of sig. } & \multirow{2}{*}{$\begin{array}{l}\text { Odds ratio } \\
(95 \% \mathrm{Cl})\end{array}$} \\
\hline & & Absent & Present & & \\
\hline \multirow[t]{2}{*}{ Severe combined } & Negative & $24(58.5)$ & $17(41.5)$ & \multirow{2}{*}{$\begin{array}{l}X^{2}=15.51 \\
P<0.001^{*}\end{array}$} & \multirow[t]{2}{*}{$6.28(2.42-16.28)$} \\
\hline & Positive & $9(18.4)$ & 40(81.6) & & \\
\hline \multirow[t]{2}{*}{ Sexual violence } & Negative & $33(39.8)$ & $50(60.2)$ & \multirow{2}{*}{$\begin{array}{l}x^{2}=4.39 \\
P=0.036\end{array}$} & \multirow[t]{2}{*}{ Undefined } \\
\hline & Positive & 0 & $7(100)$ & & \\
\hline \multirow[t]{2}{*}{ Emotional violence } & Negative & $28(66.7)$ & 14(33.3) & \multirow{2}{*}{$\begin{array}{l}X^{2}=30.52 \\
P<0.001^{*}\end{array}$} & \multirow[t]{2}{*}{$17.2(5.57-53.06)$} \\
\hline & Positive & $5(10.4)$ & 43(89.6) & & \\
\hline \multirow{2}{*}{$\begin{array}{l}\text { Physical } \\
\text { Violence }\end{array}$} & Negative & 30(78.9) & $8(21.1)$ & \multirow{2}{*}{$\begin{array}{l}X^{2}=50.63 \\
P<0.001^{*}\end{array}$} & \multirow[t]{2}{*}{$61.25(15.07-240.01)$} \\
\hline & Positive & $3(5.8)$ & 49(94.2) & & \\
\hline \multirow[t]{2}{*}{ Harassment } & Negative & 23(92.0) & $2(8.0)$ & \multirow{2}{*}{$\begin{array}{l}X^{2}=45.64 \\
P<0.001^{*}\end{array}$} & \multirow[t]{2}{*}{$63.25(12.84-90.8)$} \\
\hline & Positive & $10(15.4)$ & 55(84.6) & & \\
\hline
\end{tabular}

$x^{2}=$ chi-square test

*Statistically significant if $P<0.05$ 


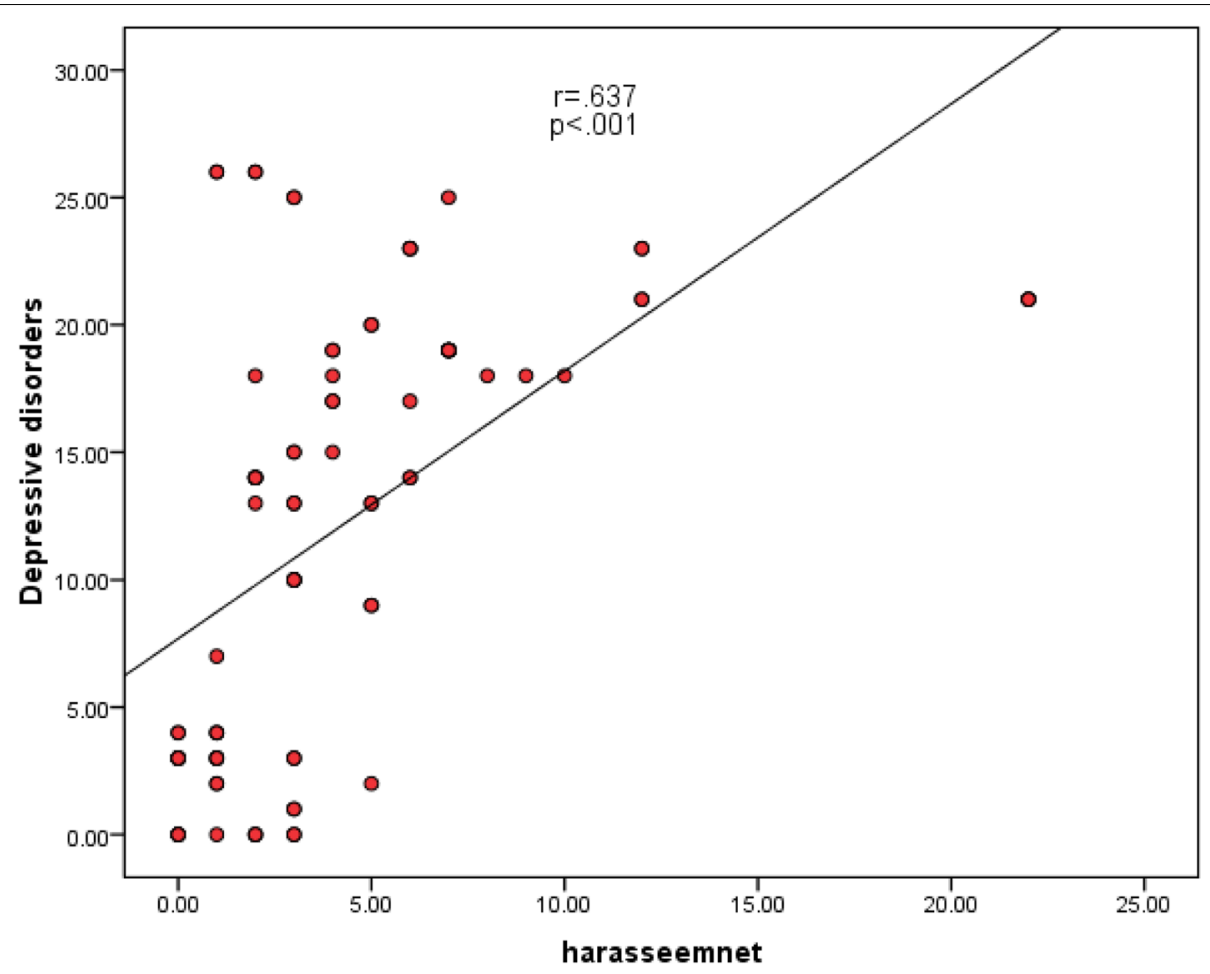

Fig. 5 Scatter diagram showing a correlation between harassment and depressive disorder

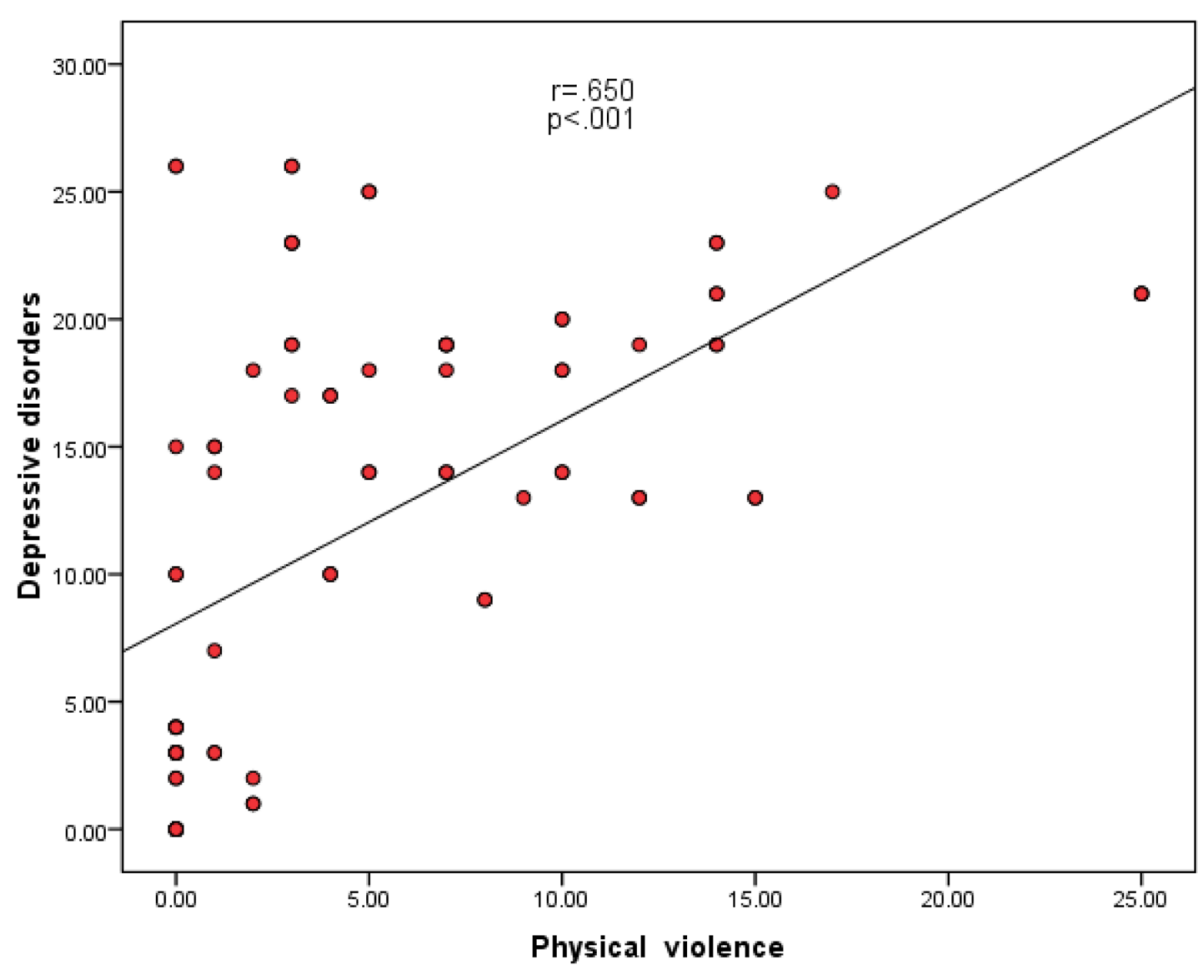

Fig. 6 Scatter diagram showing correlation between physical violence and depressive disorder 


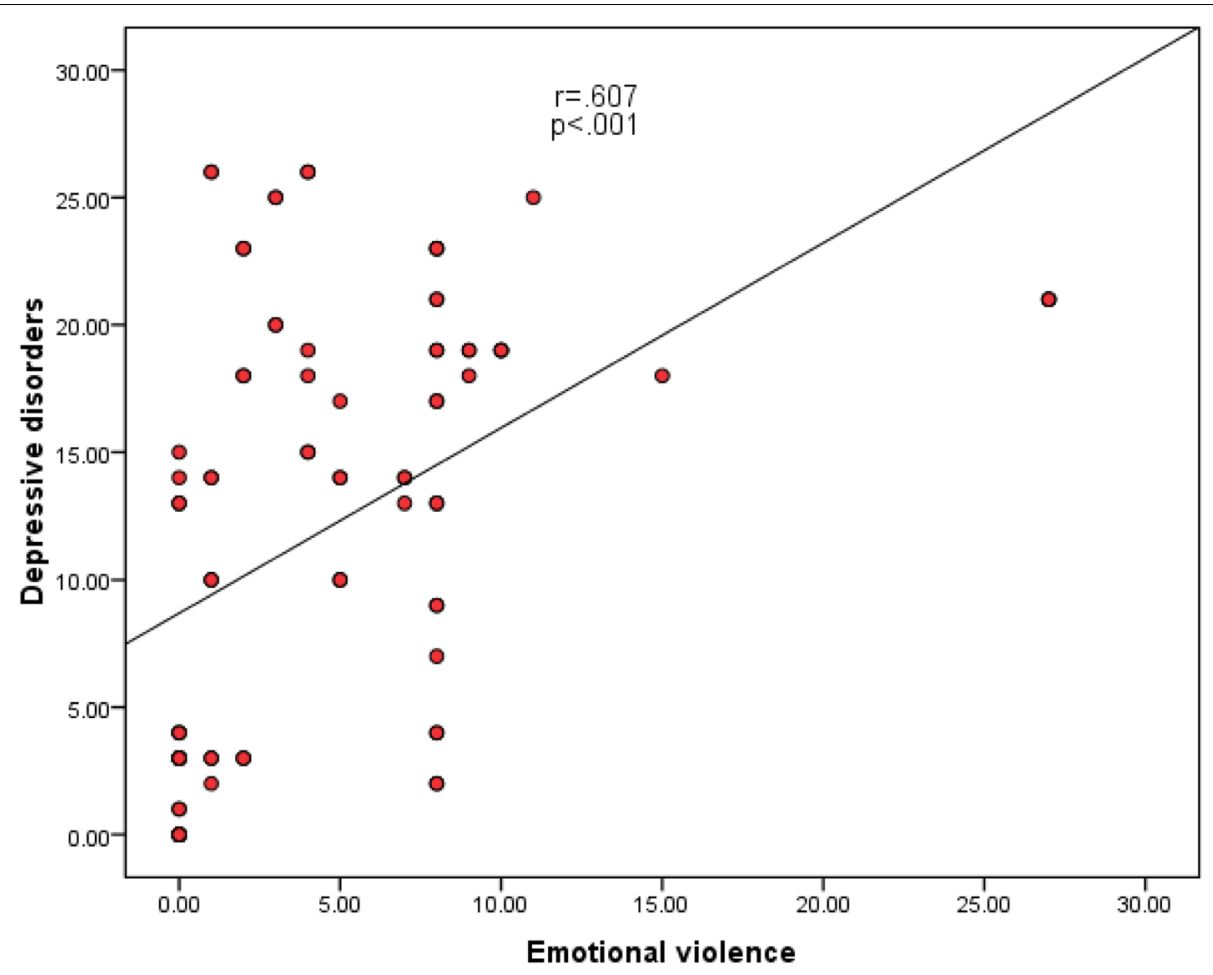

Fig. 7 Scatter diagram showing correlation between emotional violence and depressive disorder

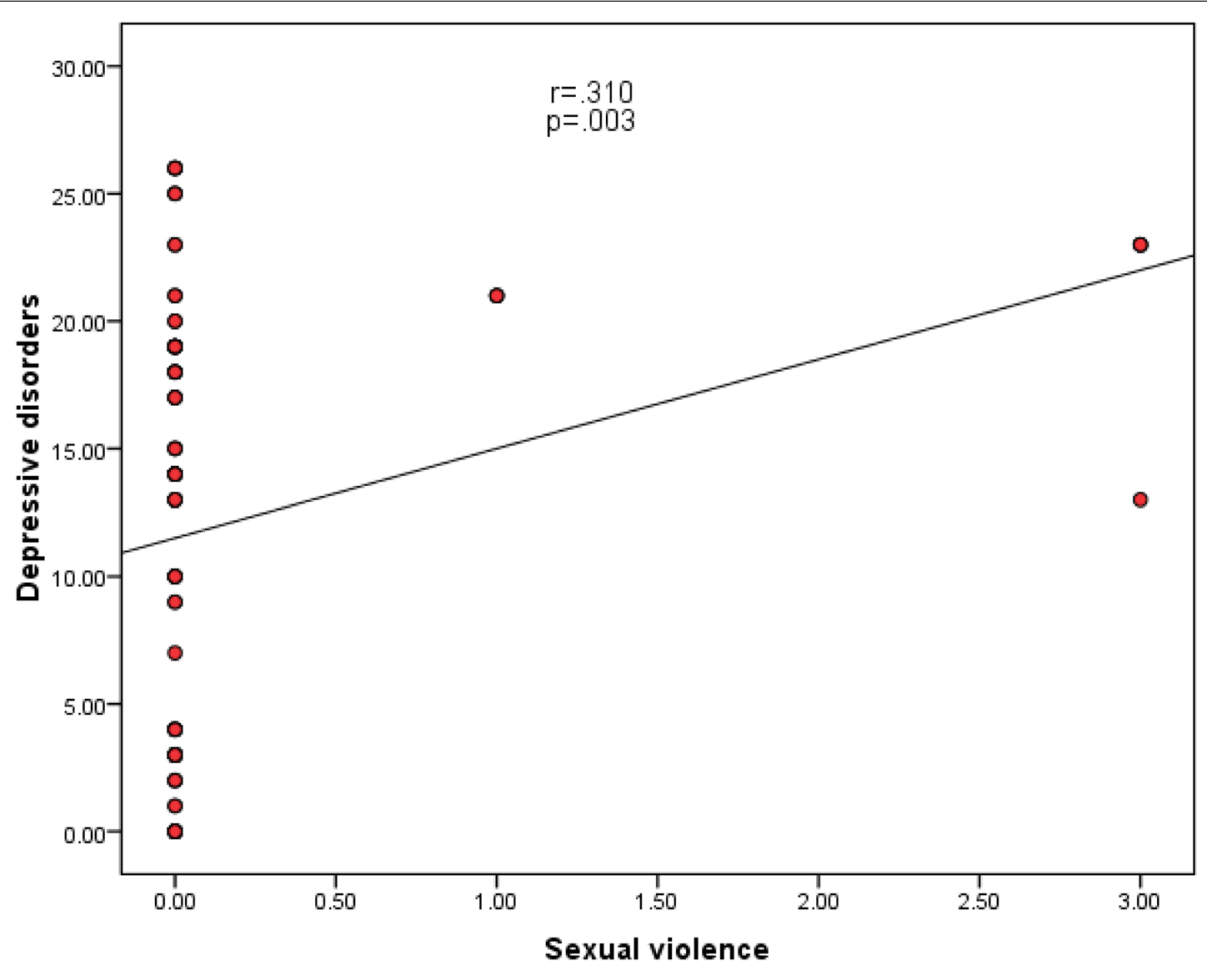

Fig. 8 Scatter diagram showing correlation between sexual violence and depressive disorder 
Table 8 Correlation between PTSD, depressive disorders, and violence types among studied females

\begin{tabular}{llll}
\hline & PTSD & $\begin{array}{l}\text { Depressive } \\
\text { disorders }\end{array}$ \\
\hline Sever combined & $\mathrm{R}$ & $.347^{*}$ & $.490^{*}$ \\
Sexual violence & $\mathrm{P}$ & .001 & $<.001$ \\
Emotional violence & $\mathrm{R}$ & $.393^{*}$ & $.310^{*}$ \\
& $\mathrm{P}$ & $<.001$ & .003 \\
Physical violence & $\mathrm{R}$ & $.554^{*}$ & $.607^{*}$ \\
Harassment & $\mathrm{P}$ & $<.001$ & $<.001$ \\
& $\mathrm{R}$ & $.649^{*}$ & $.650^{*}$ \\
Age/years & $\mathrm{P}$ & $<.001$ & $<.001$ \\
& $\mathrm{R}$ & $.589^{*}$ & $.637^{*}$ \\
& $\mathrm{P}$ & $<.001$ & $<.001$ \\
& $\mathrm{R}$ & -.018 & -.060 \\
& $\mathrm{P}$ & .864 & .571 \\
\hline
\end{tabular}

$r$ Spearman correlation coefficient

*Statistically significant if $P<0.05$

\section{Data analysis}

\section{Qualitative data}

- Chi-square test for comparison of two or more groups

- Monte Carlo test as correction for chi-square test when more than $25 \%$ of cells have count less than 5 in tables $(>2 \times 2)$.

\section{Spearman's correlation}

Spearman's rank-order correlation is used to determine the strength and direction of a linear relationship between two non-normally distributed continuous variables and/or ordinal variables.

\section{Discussion}

This study aimed to evaluate the prevalence of different subtypes of intimate partner violence in a group sample of married females.

Also, the current study examined the relation of intimate partner violence with subsequent depression and post-traumatic stress disorder disorders among those females, it highlights subtypes of intimate partner violence among the studied females according to the Composite Abuse Scale (CAS); the highest prevalence of the type of violence is harassment (72.2\%) followed by physical violence $(57.8 \%)$, severe combined violence (54.4\%), emotional violence $(53.3 \%)$, and finally the last one is sexual abuse (7.8\%).
A similar study [5] found that psychological violence (45\%), then physical (40\%), and finally sexual (38\%).

The same findings were confirmed by other studies [16-18].

But, it can be easily noticed that sexual violence is the least type of violence; may be due to cultural, social, and religious considerations. Maybe the prevalence is higher if the sample was taken from the gynecology and obstetrics outpatient clinic.

A higher prevalence of intimate partner violence was found in another study [19, 20] maybe because the females in the sample of this study were educated, all from urban areas. Uneducated or from rural areas perhaps different results were obtained.

The current research studied post-traumatic stress disorder distribution among studied females; the highest prevalence $(n=37,41.1 \%)$ had mild PTSD, followed by $23(25.6 \%)$ who were normal, and then $n=20(22.2 \%)$ had severe PTSD, while the least prevalence $(n=10$, 11.1\%) had moderate PTSD.

In concern to depressive disorder distribution among studied females; the highest prevalence $(n=33,36.7 \%)$ were normal, followed by $29(32.2 \%)$ who had moderate depression, $n=12(1.3 \%)$ who had severe depression, and $n=9(10.0 \%)$ had mild depression, while the least prevalence $(n=7,7.8 \%)$ had very severe depressive symptoms.

A recent study reported that psychological abuse is more related to PTSD which may be explained by psychological abuse is attacking the female self-concept [21].

Another study agreed with our results about the relation between IPV and major depression disorder suggesting that depression may occur as a result of the IPV experience [22]. A univariate analysis of post-traumatic disorders and types of violence among studied females reporting the presence of a significant positive relationship $(P<0.001)$ between severe combined, emotional, physical violence, and diagnosis of PTSD among studied females was examined.

Assessed univariate analysis of depressive disorders and types of violence among studied females revealing the presence of a significant positive relationship $(P$ $<0.001$ ) between severe combined, emotional, physical violence, harassment, and diagnosis of depressive disorder among studied females.

Not surprisingly, the examined females reported symptoms of depression and PTSD appeared as a prevalent concern in the current study. Several studies [23, 24] confirmed these findings.

Finally, these results should not be considered as magnifying the negative effect of IPV on females but should be regarded as females are exposed to the burden of IPV and should be helped empowered in various ways such as providing psychiatric counselling for those females. 
Therapeutic interventions either psychotherapy or pharmacotherapy especially group therapy promise in helping victims of IPV to overcome this painful experience.

Before we conclude, we would like to discuss the limitations of this study; the first limitation is the small sample size. Future research should be applied to a larger sample. Another limitation is the presence of important factors which may affect this issue such as education, no of children, age, occupation, and cigarette smoking of the intimate partner.

\section{Conclusions}

This study found that the prevalence of intimate partner violence among the studied group of females is high. In addition, the presence of a strong relationship between all types of intimate partner violence and the diagnosis of PTSD and depressive disorder among studied females.

Potential implications: these results can be applied clinically. These results should not be considered as magnifying the negative effect of IPV on females but should be regarded as females are exposed to the burden of IPV and should be helped empowered in various ways such as providing psychiatric counselling for those females. Therapeutic interventions either psychotherapy or pharmacotherapy especially group therapy promise in helping victims of IPV to overcome this painful experience.

\section{Abbreviations}

IPV: Intimate partner violence; PTSD: Post-traumatic stress disorder; CAS: Composite Abuse Scale; HDRS: The Hamilton Depression Rating Scale; PDS: Post-Traumatic Stress Diagnostic Scale.

\section{Acknowledgements}

The author is appreciative to all the participants in this study.

\section{Author's contributions}

Y.S: prepared the study design, conducted the psychiatric assessment, collected and interpreted the data, and wrote and revised the manuscript. The author read the final draft and agreed about its contents.

\section{Funding}

No funds were received for this study.

\section{Availability of data and materials}

Data are available with the request from the corresponding author.

\section{Declarations}

\section{Ethics approval and consent to participate}

All subjects signed a written informed consent form before joining the study. This study was submitted to the Institutional Research Board-IRB, Faculty of Medicine, Mansoura University, reference code is R.21.06.1364.

\section{Consent for publication}

Not applicable.

\section{Competing interests}

The author declares competing interests.
Received: 20 August 2021 Accepted: 17 October 2021

Published online: 23 November 2021

\section{References}

1. UNODC. 2018. UN Joint Global Programme calls for coordinated, multisectoral responses to gender-based violence. Also available on[URL: https://www.unodc.org/unodc/en/frontpage/2018/May/un-jointglobalprogramme-calls-for-coordinated-multi-sectoral-responses-to-genderbased-violence.html]

2. World Health Organization (2010) Preventing intimate partner and sexual violence against women: taking action and generating Evidence 11. World Health Organization, Geneva

3. Barnett, OW., Miller-Perrin, CL., Perrin RD. (2011) Family violence across the lifespan: an introduction. Thousand Oaks, CA. Sage, WHO (2005) Addressing violence against women and achieving the Millennium Development Goals. WHO/FCH/GWH/05.

4. Follingstad DR, Rogers J (2014) The nature and prevalence of partner psychological abuse in a national sample of adults. Violence and Victims 29:3-23 https://doi.org/10.1891/0886-6708.09-160

5. Agumasie S., Belachew T., Abdulahi, M. (2013) What factors are associated with recent intimate partner violence? multi-country study on women's health and domestic violence. BMC Public Health (11):1471-2458.

6. Wakefield S. (2017) Transformative and feminist leadership for women's rights. Boston, Oxfam.Retrieved from https://www. oxfamamerica. org/ explore

7. Bacchus LJ, Ranganathan M, Watts C, Devries K (2018) Recent intimate partner violence against women and health: a systematic review and meta-analysis of cohort studies. BMJ Open 8(7)e019995

8. Hegarty K, Bush R, Sheehan M (2005) The Composite Abuse Scale: further development and assessment of reliability and validity of a multidimensional partner abuse measure in clinical settings. Violence Victims 20(5):529-547

9. Hegarty K, Sheehan M, Schonfeld C (1999) A multidimensional definition of partner abuse: development and preliminary validation of the Composite Abuse Scale. J Fam Violence 14(4):399

10. Patricia E (2010). Verbally abusive relationship, the : how to recognize it and how to respond. Adams Media Corporation. ISBN 978-1-4405-0463-1. OCLC 903230510

11. Hamilton M (1980) Rating depressive patients. J Clin Psychiatry. (41): 21-24 PMID 7440521.

12. Fatim L (1994) Hamilton Depression Rating Scale. Alanglo library, Egypt

13. Foa EB. (1995) Posttraumatic Stress Diagnostic Scale Manual. National Computer Systems Inc, Epub (2008) Aug 20. Pmid: 18718671; Pmcid: Pmc2683387.

14. Norris AE, Aroian KJ (2008) Assessing reliability and validity of the Arabic language version of the Post-Traumatic Diagnostic Scale (PDS) symptom items. Psychiatry Res. 160(3):327-334. https://doi.org/10.1016/j.psychres. 2007.09.005

15. Abeya S, Afework Mesganaw F, Yalewalemayehu W (2011) Intimate partner violence against women in Western Ethiopia: prevalence, patterns, and associated factors. BMC Public Health 11:913

16. Ali R, Radwan R (2017) Magnitude and determinants of domestic violence against ever-married women in Sohag, Egypt. Int J Med Sci Public Health 6:1285-1291

17. Andualem H, Tsehaw A, Negash M, Negash S (2015) Prevalence and Consequences of Domestic Violence among Married Women in Sheybench Town, Bench Maji Zone, Southwest Ethiopia. Department of Public Health. J Biol Agricult Healthcare 5(13):168-75.

18. Bosiljka D, Jansen HA, Otasevic S (2010) Factors associated with intimate partner violence against women in Serbia: a cross-sectional study. J Epidemiol Community Health 64:728-735

19. Chima H, Carol U, Linus IA, Florence UC (2015) Factors associated with intimate partner violence among wives of military and civilian men in Abuja Nigeria. Sociol Mind 5:61-73. https://doi.org/10.4236/sm.2015. 52007

20. Beck JG, McNiff J, Clapp JD, Olsen SA et al (2011) Exploring negative emotion in women experiencing intimate partner violence: shame, guilt, and PTSD. Behavior therapy 42(4):740-750 
21. Valdez CE, Lim BH, Lilly MM (2013) "It's going to make the whole tower crooked": victimization trajectories in IPV. J Fam Violence 28(2):131-140

22. Devries KM, Mak JY, Bacchus LJ, Child JC et al (2013) Intimate partner violence and incident depressive symptoms and suicide attempts: a systematic review of longitudinal studies. PLoS Med 10:e1001439

23. Shamblaw AL, Cardy RE, Prost E, Harkness KL (2019) Abuse as a risk factor for prenatal depressive symptoms: a meta-analysis. Arch Women's Ment. Health 22:199-213
24. Chmielowska M, Fuhr DC (2017) Intimate partner violence and mental ill-health among global populations of Indigenous women: a systematic review. Soc. Psychiatry Psychiatry Epidemiology 52:689-704

\section{Publisher's Note}

Springer Nature remains neutral with regard to jurisdictional claims in published maps and institutional affiliations.
Submit your manuscript to a SpringerOpen ${ }^{\circ}$ journal and benefit from:

- Convenient online submission

- Rigorous peer review

- Open access: articles freely available online

- High visibility within the field

- Retaining the copyright to your article

Submit your next manuscript at $\boldsymbol{\sim}$ springeropen.com 